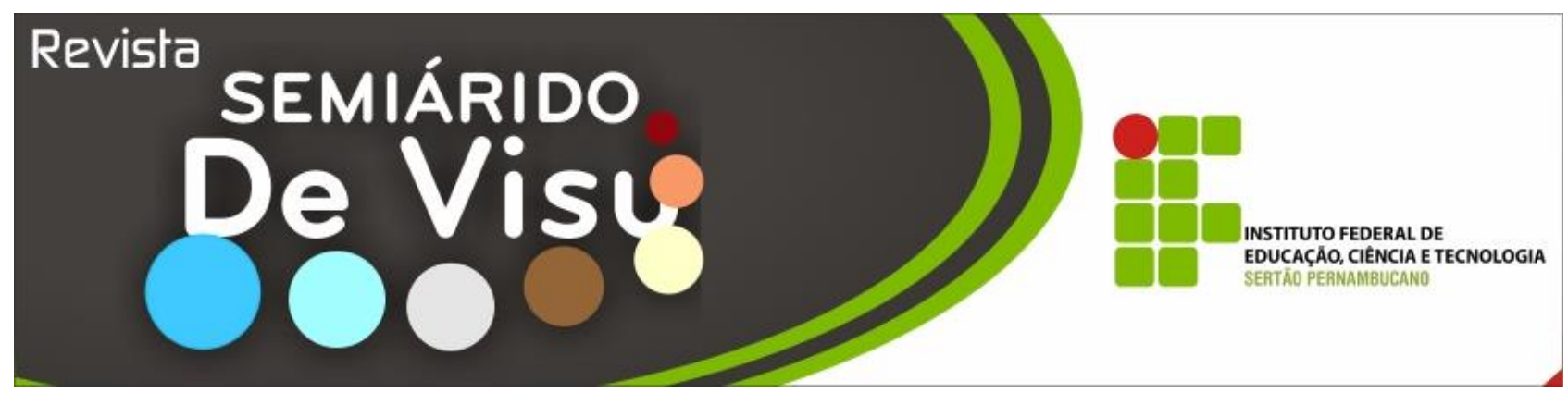

\title{
Educação contextualizada no ensino de matemática em uma escola no Semiárido de Juazeiro-BA
}

\author{
Rafael Santana Alves ${ }^{1}$, Kellison Lima Cavalcante² \\ ${ }^{1}$ Mestre em Educação, Cultura e Territórios Semiáridos - Universidade do Estado da Bahia, Campus Juazeiro, e-mail: \\ fael2270@yahoo.com.br; \\ ${ }^{2}$ Mestre em Tecnologia Ambiental - Instituto Federal do Sertão Pernambucano, Campus Petrolina, e-mail: \\ kellison.cavalcante@ifsertao-pe.edu.br.
}

\begin{abstract}
Resumo: A contextualização é um assunto recorrente e relevante atualmente. Desse modo, este trabalho aborda a Educação Contextualizada como elemento facilitador do ensino-aprendizagem de Matemática em relação às práticas docentes de acordo com a concepção dos professores da disciplina em uma escola da rede pública de ensino do município de Juazeiro-BA. Objetivou identificar as concepções dos professores quanto à Educação Contextualizada configurar-se como um elemento facilitador de acordo com o que está definido na nova proposta político-pedagógica do município. Dessa forma, tratou de uma pesquisa explicativa e que a partir de levantamento de dados de natureza qualitativa, com realização de entrevistas semiestruturadas a 08 (oito) professores que aceitaram expor suas opiniões e concepções. Os professores tomam a contextualização como uma metodologia de ensino, sendo que, para eles o ensino contextualizado pauta-se na ação do professor relacionar o conteúdo a ser trabalhado com alguma situação envolta da realidade cotidiana do educando. Foi possível constatar que todos os educadores estão tentando fazer uso da contextualização como elemento capaz de despertar no educando um interesse maior em aprender matemática.
\end{abstract}

Palavras-chave: docente; prática pedagógica, metodologia de ensino.

\section{Education contextualized in the teaching of mathematics at a school in the Semiarid of Juazeiro-BA (Brazil)}

\begin{abstract}
The context is a recurring issue important today. Thus, this work addresses the Contextualized Education as a facilitator mathematics teaching and learning in relation to teaching practices in accordance with the design of the teachers of the discipline in a school public school in the city of Juazeiro-BA. Aimed to identify the conceptions of teachers about the Contextualized Education set up as a facilitator in accordance with what is defined in the new political-pedagogical proposal of the municipality. Thus, it dealt with an explanatory research and that from lifting qualitative data, conducting semi-structured interviews with 08 (eight) teachers who agreed to express their opinions and views. Teachers take the contextualization as a teaching methodology, and for them the teaching contextualized agenda on the teacher's action relate the content to be worked with a situation shrouded the everyday reality of educating. It was found that all educators are trying to make use of contextualization as an element able to awaken in the student a greater interest in learning mathematics.
\end{abstract}

Keywords: teacher; pedagogical practice; teaching methodology. 


\section{Introdução}

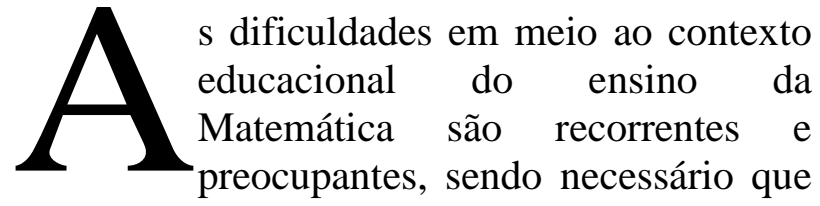
o professor busque inovação e elementos facilitadores diante de sua prática docente, fazendo com que, nos últimos anos, ocorressem grandes mudanças em todo o mundo. Dentro desse contexto, é importante ressaltar que ensinar Matemática de maneira isolada das demais disciplinas das áreas do conhecimento sem utilizar a exposição dos conteúdos de modo contextualizado e dinâmico não contribui para o desenvolvimento da formação integral do educando.

Este trabalho aborda a contextualização como elemento facilitador do ensinoaprendizagem da Matemática em relação às práticas docentes de acordo com a concepção dos professores da disciplina na rede pública de ensino do município de Juazeiro-BA. O tema é recorrente e de extrema relevância visto que o ensino dessa disciplina no momento educacional atual tem passado por um processo de transformação em que novas orientações curriculares vêm sendo implementadas, como a elaboração de novos fundamentos para a construção de Diretrizes Político-pedagógicas de educação contextualizada para a convivência com o Semiárido da Secretária de Educação e Cultura do município. Hoje, a referida localidade é destaque no movimento pela educação para a convivência com o Semiárido, uma vez que, foi sede dos primeiros encontros da região, nos quais se analisou e evidenciou o isolamento da educação escolar em relação às questões da realidade local, ou seja, a descontextualização do ensino face às especificidades do Semiárido brasileiro. Ficou evidenciado o nascimento de um movimento organizado em prol da educação contextualizada, como o surgimento de pesquisas e estudo sobre a temática.

Dessa forma, a partir de uma reflexão acerca da introdução de uma nova proposta político-pedagógica, é possível enfatizar que muitos são os desafios a serem enfrentados, sobretudo, no que se refere a resistência por parte de alguns educadores em aderir as novas ideias e, consequentemente, as novas mudanças em meio ao ensino-aprendizagem da Matemática, ou seja, a realização de práticas pedagógicas contextualizadas. No entanto, mudar a metodologia em prol do oferecimento de um ensino que contribua com a formação integral do educando é importante, uma vez que, a Matemática faz parte da vida de todas as pessoas e a aprendizagem dos seus conteúdos ganha mais significado a partir do momento que o seu ensino é imbuído da realidade sociocultural dos educandos. Este é o real significado pedagógico da contextualização.

Nesse sentido, sabendo da implementação de uma nova proposta políticopedagógica, os professores necessitam ter conhecimento sobre a temática, compreender suas finalidades e entender o seu significado para que assim possa incorporar às suas práticas docentes. Para a compreensão do ensino contextualizado, este trabalho objetivou identificar as concepções dos professores quanto à contextualização configurar-se como um elemento facilitador do ensinoaprendizagem da Matemática de acordo com o que está definido na nova proposta políticopedagógica do município de Juazeiro-BA.

\section{Revisão de Literatura}

O saber matemático caracteriza-se pela objetividade, precisão, rigor, neutralidade, universalidade, uma vez que, de acordo com Machado (2013) são esses componentes que geram visões acerca que um determinado texto matemático só seria passível de utilização quando aplicado em um nível adequado de aprendizagem e associado ao ensino de conteúdos programáticos relacionados à realidade do educando.

É essencial que o educador passe a compreender o meio em que o educando está inserido, como sendo uma proposta metodológica como expressa Groenwald (2004), uma vez que o ensino da Matemática ao não despertar o interesse do educando continua por permanecer uma temática obscura, repleta de tecnicidades, tornando a sua compreensão incompreensível, lócus de abstrações abstrusas 
o que é um problema. Segundo Cavalcante (2002, p.84) “[...] a matemática traz grandes contribuições para o desenvolvimento do aluno, pois ela tem relações estreitas com diversas áreas do conhecimento e da atividade humana", no entanto, o seu ensino deve ser contextualizado e repleto de significado. Um conteúdo não desperta a atenção do aluno se não estiver associado a um contexto prático, ou seja, a uma situação concreta e existente. Levando em consideração que a contextualização é um elemento facilitador do ensino-aprendizagem da Matemática, é fundamental compreender a concepção do seu ciclo histórico frente à realidade. Santos et al. (2011, p.2) ressaltam que:

A história da matemática pode ser
usada como ferramenta didática,
agindo como instrumento que
contextualiza, humaniza, motiva e
ajuda a formalizar conceitos. Ela é
fundamental para expor como teorias e
práticas matemáticas foram criadas,
cada uma em determinado tempo, ela é
um recurso didático que contribui para
o aprimoramento e a valorização do
aprendizado matemático, auxiliando a
desenvolver uma motivação maior por
parte dos alunos em relação ao que
está sendo estudado (SANTOS et al.,
2011, p.2).

Nesta perspectiva, ou seja, pautando-se nas considerações feitas por Santos et al. (2011), vale destacar que, ao longo da história, o ensino da Matemática sempre foi considerado uma tarefa complexa em decorrência da existência de dificuldades intrínsecas associadas a uma visão estereotipada, que se reflete desde o primeiro contado do educando com essa disciplina. Conhecer primeiro antes de julgar o saber matemático é essencial como afirmam Lopes e Ferreira (2013, p.77):

Conhecer a origem dos assuntos que se gosta é uma curiosidade natural, inerente ao ser humano. Na escola, aprende-se e há interesse por muitos temas, em todas as disciplinas. No entanto, principalmente no que se refere aos conhecimentos matemáticos, parece que não há mais nada a ser "descoberto" ou "inventado". Além disso, esses conteúdos passam a ideia de que sempre tiveram a mesma forma, abstrata e sem contextualização, do jeito que se conhece na escola (LOPES; FERREIRA, 2013, p.77).

Nesse contexto, uma educação contextualizada pautada e voltada para a convivência com o território Semiárido faz com que o educando leve para sua vida diária e prática os conhecimentos e teorias adquiridos na escola. No entanto, é importante lembrar que, de acordo com Reis (2011, p. 12):

Fazer uma educação nessa perspectiva, em que essa idéia de contexto seja o ponto de partida e de chegada, no espaço da escola urbana, ou mais especificamente, na educação do campo e na educação do Semiárido brasileiro, não é tão fácil de se concretizar, pois urge o desprendimento de várias questões e signos que estão arraigados nos sistemas e nos educadores (REIS, 2011, p. 12).

É válido destacar que a contextualização dos conteúdos matemáticos pode estimular os educandos em meio ao processo de motivação em aprender o que está sendo ensinado, sendo que, para Tufano (2001, p. 47), “a contextualização é um ato particular. Cada autor, escritor, pesquisador ou professor contextualiza de acordo com suas origens, com suas raízes, com seu modo de ver as coisas com muita prudência". A contextualização do conteúdo em si, reflete uma determinada importância face ao cotidiano vivenciado pelos educandos, uma vez que, possibilita que o aluno compreenda que aquilo que se aprender em sala de aula tem aplicação em meio a sua vida prática e o saber não se refere ao acúmulo de conhecimentos técnico-científicos, mas sim um recurso que o prepara para enfrentar os desafios impostos e existentes no mundo no qual ele (educando) vive. De acordo com o pensamento de Brousseau (1996, p. 69), evidencia-se que: 
$\mathrm{O}$ funcionamento eficaz da contextualização ocorrerá quando, ao responder as situações propostas, o aluno produz um conhecimento que poderá utilizar em outras situações. Caberá a ele, com a ajuda do professor, re-despersonalizar e re-

descontextualizar o

saber, reconhecendo que o conhecimento produzido poderá ser utilizado em outras situações, ou seja, é um saber cultural reutilizável" (BROUSSEAU, 1996, p. 69).

Diante disso, é importante ressaltar que quando o conteúdo matemático é ensinado pelo professor de maneira descontextualizada isso pode gerar desinteresse pelos educandos, como também a aprendizagem não se torna significativa, uma vez que, há um distanciamento entre o que é ensinado e a aplicação dos conteúdos na vida cotidiana do aluno, sendo que, "não é mais possível apresentar a Matemática aos alunos de forma descontextualizada, sem levar em conta que a origem e o fim da Matemática é responder às demandas de situações-problema da vida diária" (GROENWALD; FILLIPSEN, 2002, p. 18). É, justamente, o contexto que dá significado ao conteúdo e o processo de contextualização deve se basear na vida social, bem como, nos fatos vivenciados pelos educandos no seu dia a dia. A realidade é que o aluno vive num mundo regido pela natureza, como também, pelas relações sociais estabelecidas por meio da convivência, sendo que, é em decorrência desse fato que o cotidiano, o ambiente físico e social devem ser utilizados como caminho entre o que o educando vive e o que se aprende na escola.

Levando em consideração isso, o ensino-aprendizagem da Matemática contextualizada expressa nos Parâmetros Curriculares Nacionais (PCN) visa que o educando aprenda a mobilizar competências para resolver situações-problema em meio a contextos apropriados, tornando-se capaz de utilizar essa capacidade de resolução em meio à solução de problemas existentes no mundo social no qual se encontra inserido. Nesse sentido, a contextualização possibilita a aquisição de saberes essenciais para o aluno no que diz respeito à elaboração de técnicas de resolução dos mais variados problemas propostos não só no ensino-aprendizagem da Matemática, mas, também na sua vida cotidiana. Fernandes (2006, p. 6) evidencia que, em Matemática:

A contextualização é um instrumento bastante útil, desde que interpretada numa abordagem mais ampla e não empregada de modo artificial e forçado, e que não se restrinja apenas ao cotidiano do aluno. Defende-se a idéia de que a contextualização estimula a criatividade, o espírito inventivo e a curiosidade do aluno (FERNANDES, 2006, p. 6).

Considerando a afirmação de Fernandes (2006) é importante destacar que cabe ao professor em meio à definição da metodologia a ser utilizada no ensino-aprendizagem de um determinado conteúdo utilizar a contextualização como elemento estimulador da criatividade do educando, sem restringi-la a nível, somente, do cotidiano do aluno. A contextualização ganha significado a partir do momento que o professor a utiliza como elemento que possibilita a criação de condições para que à aprendizagem seja motivadora, fazendo com que sejam superados os distanciamentos entre o que é ensinado na escola e as experiências dos educandos.

\section{Material e Métodos}

O estudo aborda a questão da concepção dos professores com relação à nova proposta político-pedagógica de ensino do Município de Juazeiro-BA e as suas práticas docentes voltadas à contextualização, a partir da identificação como um elemento facilitador do ensino aprendizagem da Matemática.

Dessa forma, para obter respostas para a questão levantada foi necessário o emprego de procedimentos científicos, onde, partindo do ponto de vista do objetivo traçado, a pesquisa é de ordem explicativa e que para atender aos procedimentos técnicos considera-se como um levantamento de dados. No entanto, a 
investigação científica depende de um conjunto de procedimentos para que resultados significantes e satisfatórios sejam atingidos. Por isso, a pesquisa seguiu o método dialético, a partir da realização de entrevistas com os professores de Matemática. A abordagem considerou uma pesquisa qualitativa, preocupando em coletar opiniões e conceitos dos professores objeto de estudo.

Nesta perspectiva, torna-se necessário enfatizar que para isso foi necessário buscar um contato direto com esses professores na tentativa de identificar as suas percepções através da análise feita a respeito de seus discursos. Assim, para análise de dados foram selecionados 08 (oito) professores de Matemática do Ensino Fundamental II de uma escola da rede pública municipal de ensino de Juazeiro-BA, localizada na Zona Rural do município. Os professores entrevistados participaram efetivamente das formações pedagógicas propostas pela Secretaria Municipal de Educação no ano de 2014, que abordaram a Educação Contextualizada para Convivência com o Semiárido como tema propulsor. O Ensino Fundamental II foi escolhido por ter professores formados na área de matemática, tendo assim, maior contribuição para o desenvolvimento da pesquisa.

Nesse sentido, os professores pesquisados possuem envolvimento e participação ativa ao longo das formações pedagógicas em matemática. Ademais, todos os sujeitos selecionados foram escolhidos e, por conseguinte, convidados para participar da pesquisa em decorrência da perspectiva que eles trabalham com a contextualização no ensino-aprendizagem de matemática no Ensino Fundamental II da Escola em estudo.

\section{Resultados e Discussões}

As dificuldades no ensinoaprendizagem da Matemática já existem há vários anos e conforme expressa a literatura os obstáculos devem ser superados tendo por base o questionamento e análise feita pelos próprios alunos, como também, por meio da reflexão realizada pelos professores frente ao seu trabalho. Se há dificuldade existe ela tem que ser superada para que à aprendizagem de fato ocorra e nada melhor do que o educando para destacar quais são os motivos que às geram. Ao adentrar na sala de aula, é possível constatar que muitos alunos sentem dificuldade em aprender Matemática em decorrência do fato que os seus conteúdos são ensinados de modo isolado das demais disciplinas por muitos professores, bem como, em muitos casos que não há uma preocupação desses profissionais em relacionar o conteúdo ensinado com alguma situação cotidiana presente no dia a dia dos educandos.

D’Ambrósio (2001) ressalta que o cotidiano está impregnado dos saberes e fazeres próprios da cultura. Dessa forma, para a resolução de questionamentos da nossa realidade utilizamos materiais e conhecimentos provenientes da cultura que estamos inseridos, como método de apropriar-se mais facilmente.

Nesta perspectiva, é importante enfatizar que a Matemática se encontra presente na vida de todas as pessoas e, é fundamental, que o professor na realização do seu trabalho consiga trazer para dentro da sala de aula situações que evidenciem a afirmação destacada por D'Ambrósio (2001). Trabalhar situações-problema tendo como base a vida cotidiana dos educandos é importante, pois facilita à aprendizagem, como também, faz com que o aluno perceba o quanto a Matemática está presente na sua vida. A partir do instante que o educador dar sentido a um determinado conteúdo matemático por meio do ato de contextualizar a aprendizagem ganha significado, sendo que, de acordo com os PCNS "a aprendizagem significativa pressupõe a existência de um referencial que permita aos alunos identificar e se identificar com as questões propostas" (BRASIL, 1999, p. 36).

Dentro desse contexto, torna-se necessário destacar que face á realização das entrevistas, bem como, das observações feitas durante o acompanhamento da rotina diária de trabalho dos professores que em meio à utilização da contextualização em suas aulas, a maior parte desses sujeitos enfatiza que os alunos de maneira geral não gostam de Matemática. Este se apresenta como um dos motivos que faz com que os educadores 
acreditem que a contextualização ao ser utilizada como elemento facilitador de ensino configura-se como uma alternativa de solucionar as dificuldades dos educandos.

Nesta perspectiva, ficou evidenciado por meio dos relatos de todos os professores que por meio da contextualização a Matemática, ou seja, os seus conteúdos se tornam mais aplicáveis em situações vivenciadas no dia a dia do educando, aproximando as teorias ensinadas em sala de aula das experiências práticas do cotidiano e, é, justamente, isso que permite uma maior compreensão pelos alunos.

Associar teorias e prática face ao processo educacional da Matemática é uma ação que deve ser desenvolvida por todos os educadores, uma vez que, como asseguram Pimenta e Lima (2004) as teorias nada mais são do que explicações provisórias da realidade vivenciada pelo educando.

Dentro desse contexto, muitas são as contribuições da contextualização no processo de ensino-aprendizagem da Matemática no momento educacional atual. A partir do momento que essa disciplina é trabalhada de maneira contextualizada o conhecimento matemático passa a ganhar sentido para o educando, uma vez que, o auxilia na compreensão e interpretação dos saberes construídos e ensinados na escola e existentes na sua vivência extraescolar. Desse modo, evidencia-se que contextualizar o ensinoaprendizagem da Matemática pode possibilitar a aprendizagem da Educação Matemática significativa para o aluno, uma vez que, promove a relação entre o que se aprende na sala de aula por meio do ensino do professor e na vida.

No decorrer das observações feitas em sala de aula, bem como, por meio do contato direto com os professores frente à realização das entrevistas, pôde-se observar que, praticamente, todos esses sujeitos construíram um conceito equivocado de contextualizar. A realidade é que a maior parte dos professores toma a contextualização como uma metodologia de ensino, sendo que, para eles o ensino contextualizado pauta-se na ação do professor relacionar o conteúdo a ser trabalhado com alguma situação envolta da realidade cotidiana do educando. No entanto, isso tem se tornado um grande problema, pois quando se é utilizado outro tipo de contexto envolto, por exemplo, no uso da etnomatemática esses mesmos professores não entendem isso como uma forma também de contextualizar e é em meio a essa situação que o conceito errôneo da contextualização se propagada cada vez mais no contexto educacional. Um dos professores expressa o que ele entende por contextualização, como destaca o Quadro 01 abaixo.

\section{Quadro 01 - Opinião do professor quanto ao seu entendimento da contextualização}

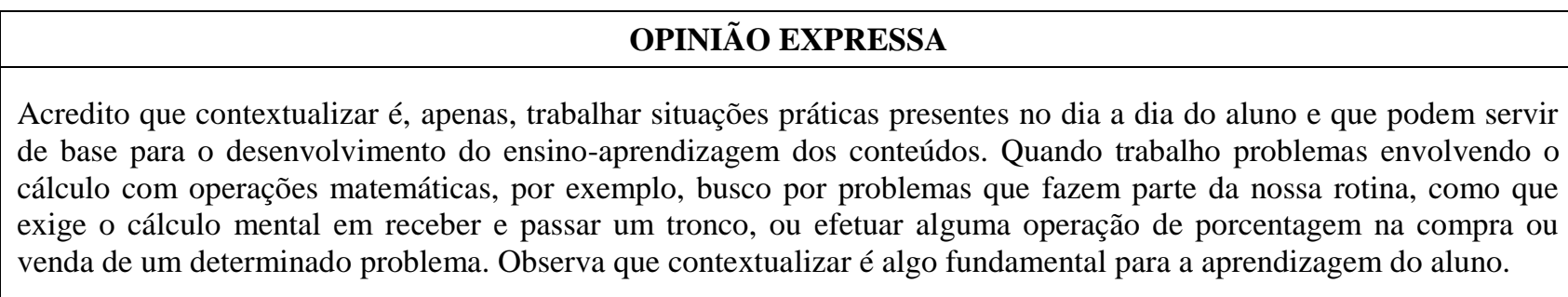

Fonte: Dados da pesquisa (2014).

Partindo do exposto acima, torna-se importante enfatizar que contextualizar vai além de trazer para sala de aula situações que estão presentes na vida cotidiana do educando. No entanto, a maior parte dos professores entrevistados, tem esse mesmo pensamento errôneo em torno do que é educação contextualizada para convivência com o semiárido.

De acordo com Martins (2006), o que está por traz da ideia de educação para a convivência com o Semiárido é a defesa de uma contextualização tanto da educação, como do ensino, das metodologias e dos processos. 
Assim, nessa perspectiva, ou seja, em meio a esse rompimento expresso por Martins (2006), bem como, levando em consideração todos os dados obtidos ao longo da pesquisa, pôde-se perceber que todos os professores acreditam e enfatizam nos seus discursos que a contextualização é sim um elemento facilitador do ensino-aprendizagem da Matemática. No entanto, esses profissionais, sujeitos desta pesquisa, encontram-se frustrados com o modo como essa nova proposta político-pedagógica foi apresentada e inserida nas instituições de ensino municipais de Juazeiro-BA. A realidade é que por meio das observações feitas em sala de aula, foi possível constatar que todos os educadores estão tentando fazer uso da contextualização como elemento capaz de despertar no educando um interesse maior em aprender matemática, ou seja, frente à prática docente desses profissionais existe a preocupação com a aprendizagem do aluno.

\section{Considerações Finais}

O ensino da Matemática, assim como de outras disciplinas deve estar associado com os saberes locais e universais que fazem parte da vida dos educandos. Com o estudo, é possível perceber que os professores vêem a contextualização como uma metodologia de ensino, que deve ser relacionada com as teorias didáticas e o cotidiano do educando. Porém, sem uma formação adequada e sem um conhecimento mínimo sobre o processo de educação contextualizada essa prática docente torna-se inviável para uma formação efetiva do aluno em relação aos assuntos matemáticos. Os professores necessitam entender as formas de contextualizar para que em meio a essa situação de relacionar apenas ao cotidiano do aluno, esquecendo da cultura, da história, da atividade econômica local e de várias outras relações não se propague um conceito errôneo da contextualização no processo educacional. Por meio das observações, foi possível constatar que todos os educadores estão tentando fazer uso da contextualização como elemento capaz de despertar no educando um interesse maior em aprender matemática, ou seja, frente à prática docente desses profissionais existe a preocupação com a aprendizagem do aluno. Com o estudo é possível dar continuidade a pesquisa sobre a educação contextualizada para a convivência com o Semiárido, podendo abordar novos questionamentos.

\section{Referências}

BRASIL. Ministério da Educação. Parâmetros Curriculares Nacionais: Matemática. Rio de Janeiro: DP\&A, 1997.

BROUSSEAU, G. Fundamentos e Métodos da Didáctica da Matemática. In: BRUN, Jean. Didática das Matemáticas. Lisboa: Instituto Piaget, 1996. Cap. 1, p. 35-113.

CAVAlCANTE, L. G. Para Saber Matemática. $2^{a}$ edição. Editora Saraiva 2002.

D’AMBROSIO, U. Etnomatemática - elo entre as tradições e a modernidade. Belo Horizonte: Autêntica, 2001. (Coleção em Educação Matemática, 1).

FERNANDES, S. da S. A contextualização no ensino de Matemática - um estudo com alunos e professores do Ensino Fundamental da Rede Particular de Ensino do Distrito Federal. $2006 . \quad$ Disponível em: https://www.ucb.br/sites/100/103/TCC/22006/S usanadaSilvaFernandes.pdf $>$ Acesso em: 15 maio 2014.

FOGAÇA， J. Contextualização. 2012. Disponível em: http://educador.brasilescola.com/trabalhodocente/contextualizacao.htm> Acesso em: 15 abril 2014.

GROENWALD, C. L. S. Perspectivas em Educação Matemática. Canoas: Ulbra, 2004.

GROENWALD, C. L. O.; FILIPPSEN, R. M. J. O meio ambiente e a sala de aula. Educação Matemática em Revista. (SBME), n.13, p3640, 2002. 
LOPES, L. S.; FERREIRA, A. L. A. Um olhar sobre a história nas aulas de matemática. Revista Abakós, Belo Horizonte, v. 2, n. 1, p. 75-88, nov. 2013.

MACHADO, N. J. Matemática e realidade: das concepções às ações docentes/ Nílson José Machado. - 8. Ed. - São Paulo: Cortez, 2013.

MARTINS, J. da S. Anotações em torno do conceito de educação para a convivência com o semiárido. In: RESAB. Educação para a Convivência com o Semiárido Brasileiro reflexões teórico-práticas da RESAB. JuazeiroBA: Secretaria Executiva da RESAB, 2006.

PIMENTA, S. G.; LIMA, M. S. L. Estágio e Docência. São Paulo: Cortez, 2012

REIS, E. dos S.; CARVALHO, L. D. (Orgs.). Educação Contextualizada: fundamentos e práticas. Printpex/ Nepec- Sab/ Selo Editorial RESAB, 2011.

SANTOS, T. R. C.; MELLO, J.; LIMA, C.; WILSMANN, L.; FERNANDES, I. M. L.; MORAES, M. C. S. História da Matemática: uma ferramenta para o desenvolvimento da aprendizagem. 2011. Disponível em: http://www.unicruz.edu.br/seminario/artigos/ag rarias/HIST\%C3\%93RIA\%20D

A\%20MATEM\%C3\%81TICA\%20UMA\%20F ERRAMENTA\%20PARA\%20O\%20DESENV OLVIMENTO\%20DA\%20APRENDIZAGEM. pdf >. Acesso em: 08 abril 2014.

TUFANO, W. Contextualização. ln: FAZENDA, I. C. Dicionário em Construção: Interdisciplinaridade. São Paulo: Cortez, 2001. 